\title{
EDUCAÇÃO NUTRICIONAL PARA PAIS E PRÉ-ESCOLARES EM UMA CRECHE
}

\section{Nutritional education for parents and preschool children in day care \\ Educación nutricional para padres y preescolares de una guardería}

\author{
Ana Angélica Romeiro Cardoso (iD) \\ Centro Universitário Estácio do Ceará - Estácio FIC - Fortaleza (CE) - Brasil
}

Maria Raquel da Silva Lima (iD

Centro Universitário Estácio do Ceará - Estácio FIC - Fortaleza (CE) - Brasil

Universidade de Fortaleza - UNIFOR - Fortaleza (CE) - Brasil

\section{Márcia Oliveira Coelho Campos iD}

Estratégia de Saúde da Família - ESF - Fortaleza (CE) - Brasil

Universidad Internacional Tres Fronteras - UnInter - Ciudad del Este - Paraguay

\section{RESUMO}

Objetivo: Descrever uma experiência de educação nutricional por intermédio de uma fábula infantil trabalhada com pais e crianças em idade pré-escolar de uma creche pública. Síntese dos dados: A experiência ocorreu no dia 15 de maio de 2018 , em que é comemorado o Dia Internacional da Família em uma creche pública no município de Fortaleza, Ceará. Houve a participação de 35 crianças, entre 2 a 4 anos, e de 30 adultos de ambos os sexos. A ação educativa desenvolveu-se a partir de uma apresentação adaptada da fábula infantil "Os três porquinhos". Construiu-se um cartaz de três metros com material de tecido não tecido (TNT), que continha uma imagem das três casas dos porquinhos. As casas de palha, madeira e tijolos foram associadas aos alimentos ultraprocessados, processados e in natura, ou minimamente processados, respectivamente. Os alimentos escolhidos baseavam-se no novo Guia Alimentar para a População Brasileira. Na medida em que os pais/responsáveis chegavam, eram acolhidos com panfletos explicativos e convidados a aproximarem-se do cartaz. Em decorrência do modo lúdico apresentado, percebeu-se facilidade na interação do preceptor e dos acadêmicos com o público-alvo, despertando a curiosidade na associação das casas ao corpo humano em relação à importância da escolha dos alimentos, entendendo-se o ambiente escolar como um local possível para promoção de saúde. Conclusão: A educação nutricional é fundamental no ambiente escolar para a promoção da alimentação saudável. O desenvolvimento de atividades lúdicas é importante para despertar o interesse das crianças, favorecendo o aprendizado.

Descritores: Educação Nutricional; Pré-escolares; Alimentação Saudável.

\section{ABSTRACT}

Objective: To describe an experience with nutritional education through a children's fable developed with parents and preschool children in a public day care center. Data Synthesis: The experience occurred on May 15, 2018, which celebrates the international day of the families, at a public day care center in the municipality of Fortaleza. A total of 35 children aged 2-4 years and 30 adults of both sexes participated. The educational action was developed from an adapted presentation of the child's fable "The three little pigs". A 3-meter poster was built using non-woven fabric to display an image of the pigs' three houses. The straw, stick and brick houses were associated with ultra-processed, processed and natural or minimally processed foods, respectively. The foods were chosen based on the Dietary Guidelines for the Brazilian Population. Parents/guardians were welcomed with informative leaflets upon their arrival and then invited to step closer to the poster. The ludic way in which the poster was presented facilitated the interaction between the target audience and the preceptor and university students and aroused the curiosity about the association of the houses with the human body in relation to the importance of food choice. The school environment was understood as a place that can potentially promote health. Conclusion: Nutritional education is fundamental in the school environment for the promotion of healthy eating. The development of ludic activities is important to arouse children's interest and hence favor learning.

Descriptors: Nutritional Education; Child, Preschool; Healthy Eating.

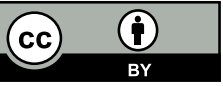




\section{RESUMEN}

Objetivo: Describir una experiencia de educación nutricional a través de una fábula infantil trabajada con padres y niños de edad preescolar de una guardería pública. Síntesis de los datos: La experiencia se dio en el día 15 de mayo de 2018 en el cual se celebra el Día Internacional de la Familia en una guardería pública del municipio de Fortaleza, Ceará. Participaron 35 niños entre los 2 y 4 años y 30 adultos de ambos los sexos. La acción educativa se ha desarrollado a partir de una presentación adaptada de la fábula infantil "Los tres cerditos". Se construyó un cartel de tres metros con material de tejido no tejido (TNT) que tenía la imagen de las tres casas de los cerditos. Las casas de paja, madera y ladrillo fueron asociadas con los alimentos ultra procesados, procesados e in natura, o mínimamente procesados, respectivamente. Los alimentos elegidos se basaban en la nueva guía alimentaria para la población brasileña. Mientras los padres/responsables llegaban eran recibidos con panfletos explicativos y invitados a acercarse del cartel. A través la manera lúdica de la presentación se percibió la facilidad de la interacción entre el preceptor y los académicos con el público-alvo despertando la curiosidad sobre la asociación de las casas con el cuerpo humano respecto la importancia de la elección de los alimentos entendiéndose el ambiente de la escuela como un sitio posible para la promoción de la salud. Conclusión: La educación nutricional es fundamental en el ambiente escolar para la promoción de la alimentación saludable. El desarrollo de actividades lúdicas es importante para despertar el interés de los niños y favorecer el aprendizaje.

Descriptores: Educación Alimentaria y Nutricional; Preescolar; Dieta Saludable.

\section{INTRODUÇÃO}

$\mathrm{Na}$ faixa etária pré-escolar, de 2 a 6 anos de vida, as crianças necessitam de um maior cuidado em relação à alimentação, principalmente por ser a fase em que ocorre a introdução de novos hábitos alimentares e de experiências sensoriais que irão motivar diretamente o padrão alimentar a ser adotado pela criança, como cheiro e sabor, além da noção de horários para a ingestão alimentar ${ }^{(1,2)}$.

Em decorrência da grande variedade de opções alimentares, os ambientes estimulam o surgimento da obesidade, condição na qual as pessoas apresentam dificuldades em trocar um alimento não saudável por um nutritivo(3) $O$ elevado índice do ganho de peso adquirido na primeira infância é um problema, pois está associado à elevação do risco de desenvolver alterações de cunho físico, social e psicológico ${ }^{(4,5)}$. Essa situação acaba reduzindo práticas alimentares locais e aumentando o consumo de industrializados, que causam impacto na saúde do indivíduo desde a produção do produto ${ }^{(6,7)}$.

De acordo com os dados do Sistema de Vigilância Alimentar e Nutricional (SISVAN) $)^{(8)}$ para a região Nordeste, no município de Fortaleza, em 2017, o indicador Índice de Massa Corpórea para Idade (IMC/I), em crianças de 1 a 5 anos, apresentou os seguintes dados: $24,02 \%$ com risco de sobrepeso; $12,90 \%$ com sobrepeso e $8,81 \%$ com obesidade.

Vale destacar que as crianças adquirem seus hábitos em dois ambientes que podem e devem estar em permanente diálogo: a família e a escola. Para as crianças e os jovens em idade escolar, a escola é fonte de informações concretas, é lugar onde se pode verificar a relevância dos fatos que estão na mídia(9).

Portanto, locais que estimulam o aprendizado, as brincadeiras e o cuidado são fundamentais para prevenir o excesso de peso e facilitar a obtenção de hábitos alimentares mais adequados. Porém esses lugares estão se tornando cada vez mais distantes do ambiente familiar, passando a fazer parte as creches e escolas na educação infantil. Na Inglaterra e na Nova Zelândia, mais de $80 \%$ de pré-escolares frequentam esses ambientes ${ }^{(10)}$

Em decorrência da fase pré-escolar ser de redução do apetite e do interesse pelos alimentos, urge a necessidade de se buscar diversificar a apresentação e as estratégias para despertar na criança a vontade de consumir os alimentos saudáveis e buscar o equilíbrio das porções oferecidas, que garantem comprovadamente os nutrientes necessários a uma vida saudável ${ }^{(11)}$.

Dessa forma, faz-se válido saber da magnitude do impacto que atividades lúdicas de promoção da saúde, voltadas para a alimentação, podem trazer para o público infantil e como os pais veem essa alternativa. Portanto, o presente artigo se propõe a descrever uma experiência de educação nutricional por intermédio de uma fábula infantil trabalhada com pais e crianças em idade pré-escolar de uma creche pública.

\section{SÍNTESE DOS DADOS}

Trata-se de uma experiência de educação nutricional direcionada a pré-escolares e seus pais em uma creche pública de Fortaleza, Ceará, Brasil. A creche selecionada faz parte da área de cobertura do campo de estágio do 
curso de Nutrição de uma universidade particular em uma Unidade de Atenção Primária à Saúde. A ação, realizada por acadêmicos e pela preceptora da disciplina Estágio Obrigatório em Saúde Pública, do curso de Nutrição, promoveu a articulação com a creche.

A transição nutricional promove modificações nos hábitos alimentares, com o aumento e facilidade de acesso aos alimentos industrializados, ricos em calorias e de menor custo. Essas mudanças elevaram a prevalência de doenças crônicas não transmíssiveis. A alimentação das pessoas passou a ser cheia de açúcares e gorduras, reduzindo a ingestão de fibras e carboidratos complexos ${ }^{(12)}$.

A Educação Alimentar e Nutricional (EAN) pode ser definida como uma intervenção que enfatiza a multiprofissionalidade e a intersetorialidade, em que o aprendizado é constante. Ela busca fazer com os indivíduos consigam mudar seus hábitos alimentares a partir de metodologias ativas e didáticas ${ }^{(13)}$. Através da EAN, as informações repassadas levam conhecimento e devem respeitar a cultura e as particularidades de cada grupo ${ }^{(14)}$.

Dessa forma, a ação educativa se desenvolveu a partir de uma apresentação adaptada da famosa fábula infantil "Os três porquinhos". A fábula original descreve a história de três porquinhos e um lobo mau, que são os personagens principais. Ao decidirem sair da casa de sua mãe, os porquinhos construíram, cada um, a sua própria casa: uma de palha, outra de madeira e a terceira de tijolos. Em desenho animado da Disney, os três porquinhos foram lançados em 1933, quando receberam os nomes Cícero, Heitor e Prático. Contudo a história já sofreu várias adaptações desde então(15).

A escolha dessa história deve-se a alusão de fragilidade representada pelas casas de palha e de madeira, e pela rigidez da casa de tijolos. Dessa forma, ilustra que o corpo humano seria semelhante a uma casa, que deve ser cuidada através da alimentação saudável, para que ela se mantenha forte, como a casa de tijolos, e que se deve evitar alimentos que deixam o corpo frágil como as casas de palha e de madeira.

As crianças se interessam por essa fábula, porque, apesar de o porquinho mais velho ser o mais inteligente por ter construído a casa de tijolos, os três personagens são, teoricamente, porquinhos pequenos e frágeis, assim como as crianças ${ }^{(16)}$. "Os três porquinhos" é uma história bastante amada pelas crianças e mostra para elas que, quando crescerem, serão mais responsáveis e deverão cuidar de si mesmas. Dessa forma, com maior conhecimento, se tem mais facilidade em vencer os desafios ${ }^{(17)}$.

Para iniciar a atividade, construiu-se um cartaz de três metros com material de tecido não tecido (TNT), que continha uma imagem das três casas dos respectivos porquinhos narrados na história. Os alimentos escolhidos para as casas baseavam-se no novo Guia Alimentar para a População Brasileira, que trata dos alimentos in natura ou minimamente processados, processados e ultraprocessados ${ }^{(18)}$.

A casa de palha foi confeccionada com palha de vassoura, sendo a porta feita com placas emborrachadas e o telhado com papel-cartão na cor laranja. Na casa de madeira, utilizou-se papel madeira, com porta de placas emborrachadas e telhado de papel-cartão na cor laranja. A casa de tijolos era feita de cartolina marrom no formato de tijolos, porta de placas emborrachadas e telhado de papel-cartão na cor laranja. No telhado da casa de palha, havia fotos de alguns dos alimentos não saudáveis mais consumidos pelas crianças. Os ingredientes expostos nessa ocasião foram alimentos ultraprocessados: biscoitos recheados; salgadinho em pacote; macarrão instantâneo; bebidas adoçadas com açúcar ou adoçantes artificiais, como refrigerantes; pó para refrescos; embutidos e outros produtos derivados de carne e gordura animal; e produtos congelados prontos para aquecer, que são nutricionalmente desbalanceados. Por conta de sua formulação e apresentação, esses alimentos tendem a ser consumidos em excesso e a substituir alimentos in natura ou minimamente processados. Além disso, as formas de produção, distribuição, comercialização e consumo afetam de modo desfavorável a cultura, a vida social e o meio ambiente(18).

$\mathrm{Na}$ casa de madeira ficaram os alimentos a serem consumidos com moderação. Embora o alimento processado mantenha a identidade básica e a maioria dos nutrientes do alimento do qual deriva, os ingredientes e os métodos de processamento utilizados na fabricação alteram de modo desfavorável a composição nutricional. A adição de sal ou açúcar, em quantidades muito superiores às usadas em preparações culinárias em geral, transforma o alimento original em fonte de nutrientes cujo consumo excessivo está associado a doenças do coração, obesidade e outras doenças crônicas ${ }^{(18)}$.

$\mathrm{Na}$ casa de tijolos ficaram os alimentos mais saudáveis, configurando os alimentos in natura ou minimamente processados, em grande variedade e predominantemente de origem vegetal, que são a base para uma alimentação nutricionalmente balanceada, saborosa, culturalmente apropriada e promotora de um sistema alimentar socialmente e ambientalmente sustentável ${ }^{(18)}$. Assim, os alimentos da casa de tijolos favoreciam o fortalecimento do organismo. Posteriormente, cada criança recebeu uma imagem dos porquinhos para pintar.

A descrição da atividade está sintetizada no Quadro I, em que para cada "casa" encontram-se descritas a classificação dos alimentos e a fonte alimentar. 
Quadro I - Descrição da atividade lúdica direcionada a pré-escolares. Fortaleza, Ceará, 2018.

\begin{tabular}{|l|l|l|}
\hline Representação & Tipos de Alimentos \\
\hline Casa de palha & Alimentos ultraprocessados & $\begin{array}{l}\text { Refrigerantes; biscoitos recheados; sorvetes; balas e guloseimas em } \\
\text { geral; bolos e misturas para bolos; refrescos; macarrão instantâneo; } \\
\text { salgadinho em pacote e produtos congelados prontos para aquecimento. }\end{array}$ \\
\hline Casa de madeira & Alimentos processados & $\begin{array}{l}\text { Alimentos em conserva; frutas em calda; queijos; pães feitos com farinha } \\
\text { de trigo; leveduras e sal. }\end{array}$ \\
\hline Casa de tijolos & $\begin{array}{l}\text { Alimentos } \\
\text { in natura ou minimamente } \\
\text { processados }\end{array}$ & $\begin{array}{l}\text { Legumes; verduras; frutas; batata; mandioca; arroz branco ou integral; } \\
\text { milho em grão; feijão de todas as cores; castanhas; carne de gado, porco } \\
\text { e aves; pescdos; leite pasteurizado; ovos e água potável. }\end{array}$ \\
\hline
\end{tabular}

A atividade ficou marcada para o final do dia, quando os pais/responsáveis iriam buscar as crianças, a fim de que houvesse a efetiva participação deles para a promoção dos cuidados com a alimentação das crianças. Assim, houve a participação de 35 crianças, entre 2 e 4 anos, e de 30 adultos de ambos os sexos. A ação ocorreu no dia 15 de maio de 2018, em que é comemorado o Dia Internacional da Família, de acordo com o calendário letivo da escola.

À medida que os pais/responsáveis iam chegando, após buscar as crianças, eram acolhidos com panfletos explicativos e convidados a se aproximarem do cartaz das casas dos três porquinhos, exposto na parede. Em decorrência do modo lúdico apresentado, percebeu-se facilidade na interação do preceptor e dos acadêmicos com o público-alvo, despertando a curiosidade da associação das casas com o corpo humano em relação à importância da escolha dos alimentos.

Os contos de fada tradicionais são ferramentas simples que permitem que pais, educadores e nutricionistas explorem inúmeros conceitos sobre alimentação e nutrição de forma lúdica e integrando diversas áreas do conhecimento. Para o sucesso da sua utilização, é importante estabelecer objetivos claros do que se pretende alcançar e adequá-los às habilidades e à capacidade de compreensão da criança, respeitando-se seu pensamento mágico e seu desenvolvimento cognitivo ${ }^{(19)}$.

Com o propósito de tornar a atividade prazerosa, tanto para as crianças quanto para os pais, procurou-se estabelecer um vínculo afetivo entre eles durante a ação de educação nutricional, visto que a competência técnica e a amorosidade são relações educativas imprescindíveis ao sucesso do aprendizado ${ }^{(20)}$.

Fazer com que a própria criança dê preferência a alimentos saudáveis deve ser um exercício contínuo de pais e educadores para que, futuramente, essa criança venha a se tornar um adulto com hábitos alimentares saudáveis. Sendo assim, as refeições e lanches devem ser momentos descontraídos e saudáveis, já que nessa fase as crianças necessitam de muita energia para crescer, brincar e estudar ${ }^{(20)}$.

Um estudo(21) mostrou a importância da parceria dos diversos atores envolvidos no processo de aprendizagem infantil. A pesquisa descreveu o quanto é válido o ensino-aprendizagem por parte dos professores, abordando temáticas de maneira lúdica na sala de aula, com metodologias ativas, como a contação de histórias, atentando-se ao cardápio do lanche escolar e fomentando a importância de ingerir tais alimentos. Além disso, ainda foi de grande valia a presença da integralidade entre os pais, professores e o nutricionista, considerado um profissional primordial nesse processo de capacitação e incentivo aos bons hábitos alimentares ${ }^{(21)}$.

Ao realizar essa atividade, entendeu-se que o ambiente escolar pode ser promotor de saúde através de práticas educativas que chamem atenção pelo visual, pelas cores, formatos e sons, que atraem as crianças, principalmente na pré-escola, e não somente pela acomodação de atividades tradicionais que envolvam a explanação de algo.

Um trabalho(2) ${ }^{(22)}$ sobre a influência de atividades educativas voltadas para a alimentação saudável, contribuindo com a alfabetização dos escolares, mostrou a importância de práticas pedagógicas inovadoras na formação das crianças. A atividade realizou-se em uma escola de Realengo, Rio de Janeiro, com vídeos da literatura infantil que abordavam a temática de alimentação saudável. Dessa forma, nota-se a relevância dos professores reinventarem suas ações. Visando mudanças ao longo do tempo, novas abordagens são essenciais para a construção e fixação do conhecimento.

O lúdico é uma excelente estratégia já que estimula a construção do conhecimento humano e a progressão das diferentes habilidades operatórias, pois se trata de uma ferramenta importante de progresso pessoal e de alcance de objetivos institucionais ${ }^{(23)}$.

Outra pesquisa ${ }^{(24)}$ elaborou uma atividade de contação de histórias na Comunidade do Gengibre, em Fortaleza, Ceará, e contou com crianças com idades entre 4 e 15 anos para abordar a história "Tainara, sua comunidade e a 
horta saudável". Essa narrativa fala sobre a vida em sociedade de uma criança que ficava doente e os moradores do território se juntavam para plantar e colher alimentos medicinais de uma horta cultivada por eles e, assim, ajudá-la a melhorar. Verificaram que todos prestavam muita atenção na história e se questionavam quais alimentos conheciam e a quais tinham acesso na comunidade. Concluíram que a forma lúdica escolhida possibilitou diálogo e contribuiu para o aprendizado, como vimos também em nossa experiência.

A contação de histórias é um valioso auxiliar na prática pedagógica de professores da educação infantil e anos iniciais do ensino fundamental. As narrativas estimulam a criatividade, a imaginação e a oralidade; facilitam o aprendizado; desenvolvem as linguagens oral, escrita e visual; incentivam o prazer pela leitura; promovem o movimento global e fino; trabalham o senso crítico, as brincadeiras de faz-de-conta, valores e conceitos; colaboram com a formação da personalidade da criança; propiciam o envolvimento social e afetivo; e exploram a cultura e a diversidade ${ }^{(25)}$.

Na cidade do Rio de Janeiro ${ }^{(23)}$, analisaram-se ações educativas nutricionais implementadas com pré-escolares em uma creche universitária na visão dos responsáveis. Quando observada a alimentação na creche, observou-se a necessidade de implantar ações de educação nutricional, a fim de promover maior aceitação do cardápio pelas crianças. Para isso, utilizou-se uma coleção de livros chamada Reino da Frutolândia e Reino das Hortaliças, além de jogos e vídeos, sendo vista como uma maneira de construir o conhecimento. Os professores consideraram ser uma atividade bem eficaz e os pais relataram melhora dos hábitos alimentares das crianças, enfatizando mais uma vez a importância da educação nutricional.

A leitura é uma potente ferramenta para a imaginação das crianças. As histórias vão ganhando cores, formatos, e ensinando de forma simples e eficaz. Essas características podem ser facilitadores para a aquisição de bons hábitos alimentares por meio de livros com temáticas sobre o ato de comer, ou seja, ao ouvir o quanto as frutas e verduras possuem cores vibrantes e distintas, com sabores agradáveis, o público-alvo da pesquisa pode se sentir mais instigado a experimentá-las ${ }^{(26)}$.

Ações que incentivam a alimentação saudável se tornam um fator positivo aos hábitos alimentares das crianças. Apesar de intervenções centrais no ambiente influenciarem nas mudanças, ainda se fazem necessárias intervenções maiores e mais constantes para ampliar o impacto(27).

Esta foi primeira atividade com adaptação de fábula realizada tanto pelos acadêmicos como pelo preceptor, e possibilitou um bom dinamismo na condução da explicação. Essa experiência proporcionou enorme satisfação no trabalho realizado, sendo destaque a grande interação pela fácil compreensão por parte dos pais e das crianças do assunto abordado. Portanto, com essa atividade, percebeu-se que o lúdico, nessa fase da vida, deve ser incentivado como uma importante ferramenta de ensino-aprendizagem. Por meio da contação de histórias, estimulou-se o desenvolvimento da imaginação e a associação com o enredo proposto, o que proporcionou, também, o incentivo a uma alimentação mais saudável.

Ressalta-se que, embora a atividade tenha atingido o objetivo para o qual ela foi planejada, houve algumas dificuldades quanto à continuação da atividade com outros alunos da creche devido ao término do estágio da turma.

\section{CONCLUSÃO}

Diante do que foi exposto, conclui-se que a infância é o período ideal para o desenvolvimento e a descoberta dos hábitos alimentares, pois é durante a fase pré-escolar que esses costumes são adquiridos. A obtenção desse conhecimento pode ser facilitada pela Educação Alimentar e Nutricional, que se torna fundamental no ambiente escolar para a promoção da alimentação saudável. A realização de atividades lúdicas foi importante para despertar o interesse das crianças, favorecendo o aprendizado.

\section{CONFLITOS DE INTERESSE}

Não há conflitos de interesses.

\section{CONTRIBUIÇÕES}

Ana Angélica Romeiro Cardoso contribuiu com a elaboração e delineamento do estudo, e a aquisição, análise e interpretação dos dados; Maria Raquel da Silva Lima contribuiu com a aquisição, análise e interpretação dos dados e Márcia Oliveira Coelho Campos contribuiu com a redação e/ou revisão do manuscrito. 


\section{REFERÊNCIAS}

1. Nicklaus $\mathrm{S}$. The role of food experiences during early childhood in food pleasure learning. Appetite [Internet]. 2016 [acesso em 2018 Nov 01];104(2016):3-9. Disponível: https://www.sciencedirect.com/science/article/pii/ S0195666315003888

2. Costa SEP, Mendonça KAN. Avaliação qualitativa de cardápios oferecidos para pré-escolares de creches do Distrito Federal. Universitas [Internet]. 2012 [acesso em 2018 Out 24];10(1):33-40. Disponível em: https:// www.publicacoesacademicas.uniceub.br/cienciasaude/article/view/1588/1644

3. Roberto CA, Swinburn B, Hawkes C, T-KHuang T, Costa SA, Ashe MJD, et al. Patchy progress on obesity prevention: emerging examples, entrenched barriers, and new thinking. Lancet [Internet]. 2015 [acesso em 2018 Nov 15];385(9985):2400-9. Disponível: https://www.sciencedirect.com/science/article/pii/ S014067361461744X

4. Di Angelantonio E, Bhupathiraju SN, Wormser D, Gao P, Kaptoge S, Gonzalez AB, et al. Body-mass index and all-cause mortality: individual-participant-data meta-analysis of 239 prospective studies in four continents. Lancet [Internet]. 2016 [acesso em 2018 Set 16];388(10046):776-86. Disponível: https://www.sciencedirect. com/science/article/pii/S0140673616301751

5. Hayes A, Chevalier A, D'Souza M, Baur L, Wen LM, Simpson J. Early childhood obesity: association with healthcare expenditure in Australia. Obesity [Internet]. 2016 [acesso em 2018 Out 20];24(8):1752-8. Disponível: https://onlinelibrary.wiley.com/doi/full/10.1002/oby.21544

6. Poti JM, Mendez MA, Ng SW, Popkin BM. Is the degree of food processing and convenience linked with the nutritional quality of foods purchased by US households?. Am J Clin Nutr [Internet]. 2015 [acesso em 2018 Set 02];101(6):1251-62. Disponível: https://academic.oup.com/ajcn/article/101/6/1251/4626878

7. Rauber F, Campagnolo PDB, Hoffman DJ, Vitolo MR. Consumption of ultra-processed food products and its effects on children's lipid profiles: a longitudinal study. Nutr Metab Cardiovasc Dis [Internet]. 2015 [acesso em 2018 Out 24];25(1):116-22. Disponível: https://www.sciencedirect.com/science/article/pii/S0939475314002609

8. Brasil. Relatórios de acesso público [Internet]. 2017 [acesso em 2018 Nov 27]. Disponível: http://dabsistemas. saude.gov.br/sistemas/sisvan/relatorios_publicos/relatorioconsumo.view.php

9. Boccaletto EMA, Mendes RT. Alimentação, atividade física e qualidade de vida dos escolares do município de Vinhedo - SP. Campinas: IPES Editorial; 2009.

10. OCDE (Organização para a Cooperação e Desenvolvimento Econômico). Education at a Glance 2015: indicadores da OCDE. [Internet]. Paris: OCDE Publicação; 2015 [acesso em 2018 Nov 20]. Disponível em: https://www.oecd-ilibrary.org/docserver/eag-2015 en.pdf?expires=1547599370\&id=id\&accname=guest\&check sum=0CED9B7CE2DF6D53E08689288C521213

11. Silveira MGG. Alimentação do pré-escolar e escolar: sugestões para merenda escolar, dicas para o preparo da lancheira, prevenção da obesidade. Petrópolis: Vozes; 2017.

12. Mendes EV. As redes de atenção à saúde. Brasília: Organização Pan-Americana da Saúde; 2011.

13. Ministério do Desenvolvimento Social e Combate à Fome (BR). Marco de Referência de Educação Alimentar e Nutricional para as Políticas Públicas [Internet]. Brasília: Secretaria Nacional de Segurança Alimentar e Nutricional; 2012 [acesso em 2019 Abr 25]. Disponível em: http://www.mds.gov.br/webarquivos/arquivo/ seguranca_alimentar/caisan/Publicacao/Educacao_Alimentar_Nutricional/1_marcoEAN.pdf

14. Ministério da Saúde (BR). Secretaria de Atenção à Saúde. Departamento de Atenção Básica. Saúde na escola. Brasília: Ministério da Saúde; 2009 [acesso em 2019 Abr 25]. Disponível em: http://189.28.128.100/ dab/docs/publicacoes/cadernos_ab/abcad24.pdf

15. Jacobs J. A história dos três porquinhos: um conto de fadas. Editora: Expresso Zahar; 2010.

16. Bettelheim B. A psicanálise dos contos de fadas. Rio de Janeiro: Paz e Terra; 1980.

17. Guadagnin A. Os três porquinhos em duas versões. Rev Educ Ideau [Internet]. 2017 [acesso em 2018 Mar 30];12(26):1-17. Disponível: https://www.ideau.com.br/getulio/restrito/upload/revistasartigos/392_1.pdf 
18. Ministério da Saúde (BR). Secretaria de Atenção à Saúde. Departamento de Atenção Básica. Guia alimentar para a população brasileira [Internet]. Brasília: Ministério da Saúde; 2014 [acesso em 2018 Dez 22]. Disponível em: http://bvsms.saude.gov.br/bvs/publicacoes/guia_alimentar_populacao_brasileira_2ed.pdf

19. Juzwiak CR. Era uma vez: um olhar sobre o uso dos contos de fada como ferramenta de educação alimentar e nutricional. Interface (Botucatu) [Internet]. 2013 [acesso em 2018 Nov 02];17(45):473-84. Disponível em: http://www.scielo.br/scielo.php?pid=s1414-32832013000200019\&script=sci_abstract\&tlng=pt

20. Freire P. Pedagogia da autonomia: saberes necessários à prática educativa. $23^{\mathrm{a}}$ ed. São Paulo: Paz e Terra; 1996.

21. Teixeira ALS. A relação do cuidar e educar através da alimentação saudável na educação infantil [Internet]. 2015 [acesso em 2018 Nov 02]. Disponível em: https://monografias.ufrn.br/jspui/ bitstream/123456789/2065/6/A\%20rela\%C3\%A7\%C3\%A30\%20do\%20cuidar\%20e\%20educar\%20 atrav\%C3\%A9s\%20da\%20alimenta\%C3\%A7\%C3\%A30\%20saud\%C3\%A1vel\%20na\%20educa\%C3\%A7\%C3\%A30\%20infantil_Artigo_2015.pdf

22. Drago VSR. Alimentação saudável: um relato de atividades além dos textos informativos. Rev Cad Educ Bas [Internet]. 2016 [acesso em 2018 Out 24];1(2):29-40. Disponível em: http://www.cp2.g12.br/ojs/index.php/ cadernos/article/view/792

23. Azevedo EA, Sá SPC, Lavoyer CE. Ações em educação nutricional com crianças em creche universitária - percepção dos responsáveis e dos professores sobre o lúdico. Rev Pesqui Cuid Fundam [Internet]. 2014 [acesso em 2018 Nov 02];6(4):1419-36. Disponivel em: https://www.redalyc.org/html/5057/505750770010/

24. George K. Educação em saúde, contação de história como metodologia de educação nutricional na comunidade. $9^{\circ}$ Mostra de Pesquisa em Ciência e Tecnologia; 2017; 8 - 12 maio; Fortaleza, Brasil. Fortaleza: Even3/Devry Brasil; 2017.

25. Sousa LO, Bernardino AD. A contação de histórias como estratégia pedagógica na educação infantil e ensino fundamental. Rev Educere et Educare [Internet]. 2011 [acesso em 2018 Out 24];6(12):235-49. Disponível: http://e-revista.unioeste.br/index.php/educereeteducare/article/view/4643

26. Ribeiro SRP, Ribeiro FD Filho. A Literatura infantil e alimentação saudável com foco na memória sensorial. Letras Escreve [Internet]. 2016 [acesso em 2018 Nov 03];6(1):436-50. Disponível em: https:// periodicos.unifap.br/index.php/letras/article/view/2424

27. Matwiejczyk L, Mehta K, Scott J, Tonkin E, Coveney J. Characteristics of effective interventions promoting healthy eating for pre-schoolers in childcare settings: an umbrella review. Nutrients [Internet]. 2018 [acesso em 2018 Set 16];10(3):293. Disponível em: https://www.mdpi.com/2072-6643/10/3/293/htm

\author{
Endereço para correspondência: \\ Ana Angélica Romeiro Cardoso \\ Centro Universitário Estácio do Ceará - Estácio FIC \\ Rua Eliseu Uchôa Beco, 600 \\ Bairro: Água Fria \\ CEP: 60810-270 - Fortaleza - CE - Brasil \\ E-mail: anaromeirocardoso@gmail.com
}

Como citar: Cardoso AAR, Lima MRS, Campos MOC. Educação nutricional para pais e pré-escolares em uma creche. Rev Bras Promoç Saúde. 2019;32:8926. 